\title{
Corrigendum: Home at Airbus
}

\author{
${ }^{1}$ Relly Victoria Virgil Petrescu, ${ }^{2}$ Raffaella Aversa, ${ }^{3}$ Bilal Akash, ${ }^{4}$ Juan M. Corchado, ${ }^{2}$ Antonio Apicella and \\ ${ }^{1}$ Florian Ion Tiberiu Petrescu
}

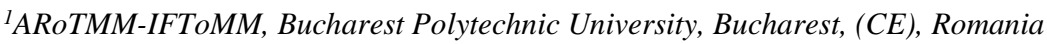

${ }^{2}$ Advanced Material Lab, Department of Architecture and Industrial Design,

Second University of Naples, 81031 Aversa (CE), Italy

${ }^{3}$ Dean of School of Graduate Studies and Research, American University of Ras Al Khaimah, UAE

${ }^{4}$ University of Salamanca, Spain

Correction to: Journal of Aircraft and Spacecraft Technology

http://doi.org/10.3844/jastsp.2017.97.118, published online 04 July 2017; updated 29

April 2019

The original version of this Article contained Mr. MirMilad Mirsayar as a Co-

Author. Mr. Mirsayar has not contributed to the preparation and publication of this manuscript.

These errors have now been corrected in the HTML and PDF versions of the Article. http://doi.org/10.3844/jastsp.2017.97.118. 